\title{
The association of dry eye syndrome and psychiatric disorders: a nationwide population-based cohort study
}

Chiao-Ying Liang ${ }^{1,2+}$, Wai-Man Cheang ${ }^{3+}$, Chun-Yuan Wang ${ }^{1}$, Keng-Hung Lin ${ }^{1}$, Li-Chen Wei ${ }^{1}$, Yu-Yen Chen ${ }^{1}$ and Ying-Cheng Shen ${ }^{1 *}$

\begin{abstract}
Background: Several previous studies reported a greater prevalence of dry eye syndrome (DES) among patients with psychiatric diseases. The aim of this study is to investigate the prevalence and risk factors of DES in patients with psychiatric disorders (PD) using nationwide population-based data in Taiwan.

Methods: This population-based cohort study retrospectively identified patients with PD from 1997 to 2011. Patients with both PD and DES served as the DES cohort, and PD patients without DES comprised the non-DES cohort. PD was defined as a diagnosis of PD (ICD-9-CM 290-319) made by psychiatrists only, with at least three consecutive outpatient visits or at least one inpatient visit. DES was defined as a diagnosis of DES (ICD-9-CM 375.15) and a prescription for an eye lubricant (anatomical therapeutic chemical code, ATC code: S01XA). The main outcome measures were the prevalence of DES in these patients and associated risk factors.

Results: A total of 75,650 patients with PD (3665 in the DES cohort and 71,985 in the non-DES cohort) were included in the final analysis. The majority of patients in the DES group were women (72.6\%), compared the nonDES group (57.8\%). The mean age of patients in the DES cohort was $62.2 \pm 14.9$, which was significantly older than those in the non-DES group (50.9 \pm 17.5$)$. The patients with DES had a significantly greater likelihood of having dementia, bipolar disorder, depression, and neurotic disorders. Conditional regression analyses revealed that patients with dry eye disease were more likely to have schizophrenia $(\mathrm{OR}=1.34)$, bipolar disorder $(\mathrm{OR}=1.9)$, depression $(\mathrm{OR}=1.54)$, and neurotic disorders $(\mathrm{OR}=1.62)$. In addition, patients with DES were more likely to use 1st generation anti-psychotics $(O R=1.28)$ and had a lower risk of using 2 nd generation anti-psychotics $(O R=0.64)$.
\end{abstract}

Conclusion: The study demonstrated that among PD patients, DES is highly prevalence in certain subtypes of PD, such as depression, bipolar disorder, and neurotic disorders, after adjusting for the comorbidities.

Keywords: Dry eye syndrome, Psychiatric disorders, Bipolar, Population-based

\footnotetext{
* Correspondence: cyl0415@yahoo.com.tw

${ }^{\dagger}$ Chiao-Ying Liang and Wai-Man Cheang contributed equally to this work. 'Department of Ophthalmology, Taichung Veterans General Hospital, 1650 Taiwan Boulevard Sect. 4, Xitun Dist, Taichung 40705, Taiwan, Republic of China

Full list of author information is available at the end of the article
}

(C) The Author(s). 2020 Open Access This article is licensed under a Creative Commons Attribution 4.0 International License, which permits use, sharing, adaptation, distribution and reproduction in any medium or format, as long as you give appropriate credit to the original author(s) and the source, provide a link to the Creative Commons licence, and indicate if changes were made. The images or other third party material in this article are included in the article's Creative Commons licence, unless indicated otherwise in a credit line to the material. If material is not included in the article's Creative Commons licence and your intended use is not permitted by statutory regulation or exceeds the permitted use, you will need to obtain permission directly from the copyright holder. To view a copy of this licence, visit http://creativecommons.org/licenses/by/4.0/ The Creative Commons Public Domain Dedication waiver (http://creativecommons.org/publicdomain/zero/1.0/) applies to the data made available in this article, unless otherwise stated in a credit line to the data. 


\section{Background}

Dry eye syndrome (DES) is a common ocular surface disease worldwide. It is a multifactorial disease of tears and ocular surface (DEWS 2007), causing irritation, blurred vision, burning, and foreign body sensation which affect patients' work, daily activities, quality of life, and emotions $[1,2]$.

Several previous epidemiological studies reported a greater prevalence of DES among patients with psychiatric diseases, such as depression, anxiety, and bipolar disorder [3-7]. However, information on the potential association between psychiatric disorders (PD) and DES is limited. Understanding of the interactions and chronology between PD, anti-psychotics, and DES is crucial for the integrated care of these patients. In the current study, we aim to investigate the prevalence and risk factors of DES in patients with psychiatric disorders using a nationwide population-based database from 1997 to 2011 in Taiwan.

\section{Methods}

\section{Data source}

The data were obtained from Taiwan's National Health Insurance Research Database (NHIRD). The Taiwan's National Health Insurance (NHI) program was established on March 1, 1995, and currently provides health care coverage for $99 \%$ of the country's population, approximately 23 million people. In this study, we used the Longitudinal Health Insurance Database 2010 (LHID2010), a subset of the NHIRD, comprising 1,000,000 randomly selected NHI beneficiaries. Patients' demographic data including gender, date of birth, income level, and healthcare data including diagnostic codes, drug prescriptions, and medical procedures contained in the database and are made available to researchers. To protect patients' privacy, all personally identifiable information is encrypted prior to release. The NHI records diagnoses according to the International Classification of Diseases, 9th Revision, Clinical Modification (ICD-9-CM).

\section{Ethics statement}

The study was approved by the Institutional Review Board of Taichung Veterans General Hospital, Taichung, Taiwan (CE13152B-6). In this study, the requirement for informed consent was waived because the patients' original identification numbers were anonymized by encryption.

\section{Study population}

This population-based cohort study retrospectively identified patients with PD (ICD-9-CM 290-319) from 1997 to 2011 from the LHID2010. We defined PD diagnoses as those made by psychiatrists only, with at least three consecutive outpatient visits or at least one inpatient visit. Patients with both PD and DES (ICD-9-CM 375.15) served as the DES cohort, and PD patients without DES comprised the non-DES cohort. DES was defined as a diagnosis of DES and a prescription for an eye lubricant (anatomical therapeutic chemical code, ATC code: S01XA). Subjects who had a diagnosis of DES prior to the diagnosis of PD were excluded from this study. In addition, we excluded patients younger than 18 years and any PD diagnosis related to children or infants (ICD-9-CM 299, 312-316). Moreover, patients with rheumatoid arthritis (RA), systemic lupus erythematosus

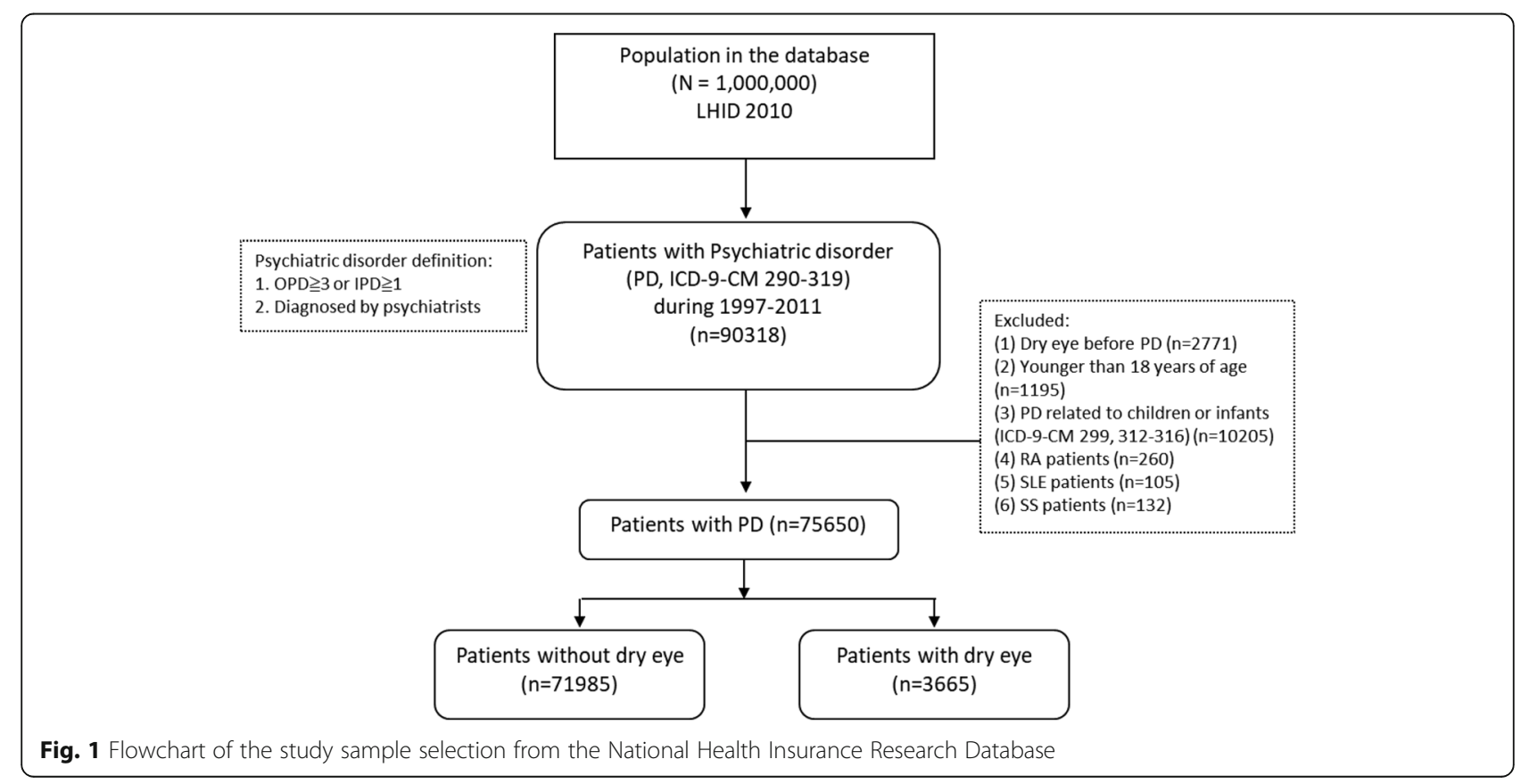


Table 1 Baseline characteristics of PD patients with and without dry eye for the period 1997-2011

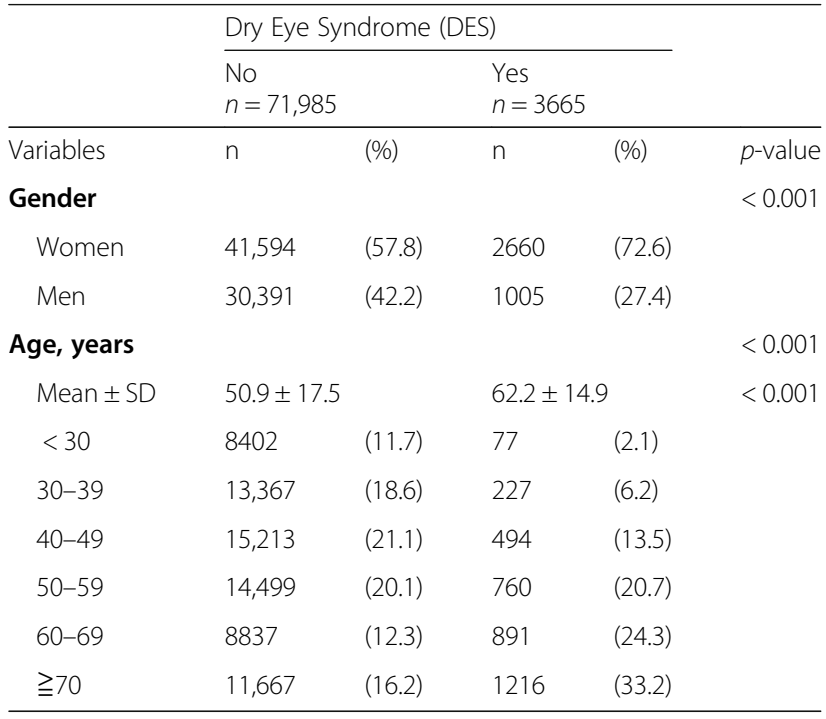

(SLE), and Sjogren's syndrome (SS) patients were also excluded.

\section{Main measure outcomes}

The main outcome measures were the prevalence of DES in PD patients and associated risk factors.

\section{Statistical analysis}

The statistical analyses were conducted using the SAS 9.3 statistical package (SAS Institute Inc., NC, USA). We used Pearson's Chi-square tests to compare the prevalence rates of different PD among patients with and without DES. In addition, the odds ratio (OR) and 95\% confidence interval (CI) for gender, age, and each subtype of the PD were conducted to calculate the risk among patients with and without DES. A $p$-value $<0.05$ in 2-tailed tests was defined as significant.

\section{Results}

Among the 1,000,000 subjects in the database, 90,318 patients were identified as being diagnosed with a PD (Fig. 1). We excluded 14,668 patients who had a diagnosis of DES prior to the diagnosis of PD $(n=2771)$, were younger than 18 years $(n=1195)$, had a PD diagnosis related to children or infants $(n=10,205)$, or had a diagnosis of RA $(n=260)$, SLE $(n=105)$, or SS $(n=132)$. The remaining 75,650 patients with PD (3665 in the DES cohort and 71,985 in the non-DES cohort) were included in the final analysis.

The baseline characteristics of the patients in the two groups are compared in Table 1 . The majority of patients in the DES group were women (72.6\%). The mean age ( \pm standard deviation) of the patients in the DES cohort was $62.2 \pm 14.9$, which was significantly older than that of the non-DES group $(50.9 \pm 17.5)$.

The prevalence rates of the different diagnoses of PD in patients with and without DES are shown in Table 2. The patients with DES had significantly greater prevalence rates of dementia, bipolar disorder, depression, and neurotic disorders. In contrast, prevalence rates of drug or alcoholic psychosis, schizophrenia, and psychiatric retardation were lower in DES patients. No significant differences in the prevalence rates of paranoid

Table 2 Psychiatric disorder conditions as defined by ICD-9-CM in PD patients with and without dry eye for the period 1997-2011

\begin{tabular}{|c|c|c|c|c|c|c|}
\hline \multirow[b]{3}{*}{ Psychiatric disorder condition } & \multirow[b]{3}{*}{ (ICD-9-CM) } & \multicolumn{4}{|c|}{ Dry Eye Syndrome } & \multirow[b]{3}{*}{$p$-value } \\
\hline & & \multicolumn{2}{|c|}{$\begin{array}{l}\text { No } \\
n=71,985\end{array}$} & \multicolumn{2}{|c|}{$\begin{array}{l}\text { Yes } \\
n=3665\end{array}$} & \\
\hline & & $n$ & $(\%)$ & $n$ & $(\%)$ & \\
\hline Dementia & $(290,331.0,331.2)$ & 7426 & $(10.3)$ & 534 & $(14.6)$ & $<0.001$ \\
\hline Alcoholic psychoses & (291) & 1707 & $(2.4)$ & 35 & $(1.0)$ & $<0.001$ \\
\hline Drug psychoses & (292) & 1339 & $(1.9)$ & 38 & $(1.0)$ & $<0.001$ \\
\hline Schizophrenia & (295) & 4242 & (5.9) & 151 & $(4.1)$ & $<0.001$ \\
\hline Bipolar disorder & (296) & 2968 & $(4.1)$ & 267 & $(7.3)$ & $<0.001$ \\
\hline Major depression & $(296.2,296.3)$ & 17,001 & (23.6) & 1180 & $(32.2)$ & $<0.001$ \\
\hline Paranoid states & $(297)$ & 1822 & $(2.5)$ & 90 & $(2.5)$ & 0.777 \\
\hline Neurotic disorders & $(300)$ & 59,528 & $(82.7)$ & 3400 & $(92.8)$ & $<0.001$ \\
\hline Obsessive-compulsive disorders & $(300.3)$ & 2059 & $(2.9)$ & 109 & $(3.0)$ & 0.687 \\
\hline Minor depression & $(300.4,309.0,309.1,311)$ & 38,542 & $(53.5)$ & 2382 & $(65.0)$ & $<0.001$ \\
\hline Mild mental retardation & $(317)$ & 1136 & $(1.6)$ & 17 & $(0.5)$ & $<0.001$ \\
\hline Other specified mental retardation & (318) & 949 & $(1.3)$ & 4 & $(0.1)$ & $<0.001$ \\
\hline Unspecified mental retardation & (319) & 1266 & $(1.8)$ & 16 & $(0.4)$ & $<0.001$ \\
\hline
\end{tabular}


states and obsessive-compulsive disorders were found between patients in the DES and non-DES cohorts.

Table 3 shows the crude and adjusted OR and 95\% CI for each of the PD, comparing patients with and without DES.

Conditional regression analyses conditioned on gender and age revealed that compared to patients without DES, patients with DES were more likely to have schizophrenia $(\mathrm{OR}=1.34)$, bipolar disorder $(\mathrm{OR}=1.9)$, depression $(\mathrm{OR}=1.54)$, and neurotic disorders $(\mathrm{OR}=1.62)$. In addition, patients with DES were more likely to use 1st generation anti-psychotics $(\mathrm{OR}=1.28)$ and were less likely to use 2nd generation anti-psychotics $(\mathrm{OR}=0.64)$.

\section{Discussion}

The aim of the current study was to use a nationwide population-based database to evaluate the prevalence of DES in patients with PD and to investigate the associated risk factors for the period 1997 to 2011. We found the prevalence of DES in adult patients with PD was $4.84 \%(n=3665 / 75650)$.

Among the patients with PD in our study, female gender, older age, and a number of medical comorbidities were associated with higher risk of DES after adjustment, and the result is consistent with prior studies $[8,9]$. Furthermore, patients with DES had significantly greater risks of schizophrenia $(\mathrm{OR}=1.34)$, bipolar disease $(\mathrm{OR}=1.90)$,

Table 3 A comparison of baseline characteristics of dry eye and non-dry eye patients based on PD conditions in univariate and multivariate models

\begin{tabular}{|c|c|c|c|c|c|c|}
\hline \multirow[t]{2}{*}{ Variables } & \multicolumn{3}{|c|}{ Univariate model } & \multicolumn{3}{|c|}{ Multivariate model $^{b}$} \\
\hline & $\overline{\mathrm{OR}^{a}}$ & $(95 \% \mathrm{Cl})$ & $\overline{p \text {-value }}$ & $\overline{\mathrm{OR}}$ & $(95 \% \mathrm{Cl})$ & $\overline{p \text {-value }}$ \\
\hline \multicolumn{7}{|l|}{ Gender } \\
\hline Women & 1.00 & (reference) & & 1.00 & (reference) & \\
\hline Men & 0.52 & $(0.48-0.56)$ & $<0.001$ & 0.60 & $(0.56-0.65)$ & $<0.001$ \\
\hline \multicolumn{7}{|l|}{ Age, years } \\
\hline$<40$ & 1.00 & (reference) & & 1.00 & (reference) & \\
\hline $40-49$ & 1.85 & $(1.43-2.40)$ & $<0.001$ & 1.38 & $(1.06-1.80)$ & $<0.001$ \\
\hline $50-59$ & 3.54 & $(2.78-4.51)$ & 0.001 & 2.17 & $(1.70-2.78)$ & 0.000 \\
\hline $60-69$ & 5.72 & $(4.52-7.24)$ & $<0.001$ & 2.97 & $(2.33-3.79)$ & 0.001 \\
\hline 70-79 & 11.00 & $(8.70-13.9)$ & $<0.001$ & 5.24 & $(4.10-6.72)$ & $<0.001$ \\
\hline$\geqq 80$ & 11.37 & $(9.01-14.3)$ & $<0.001$ & 6.42 & $(4.98-8.27)$ & $<0.001$ \\
\hline \multicolumn{7}{|l|}{ Psychiatric disorder (Yes vs. No) } \\
\hline Dementia & 1.48 & $(1.35-1.63)$ & $<0.001$ & 0.73 & $(0.65-0.82)$ & $<0.001$ \\
\hline Alcoholic psychoses & 0.40 & $(0.28-0.56)$ & $<0.001$ & 0.59 & $(0.42-0.83)$ & 0.003 \\
\hline Drug psychoses & 0.55 & $(0.40-0.76)$ & $<0.001$ & 0.85 & $(0.61-1.18)$ & 0.332 \\
\hline Schizophrenia & 0.69 & $(0.58-0.81)$ & $<0.001$ & 1.34 & $(1.11-1.62)$ & 0.002 \\
\hline Bipolar disorder & 1.83 & $(1.60-2.08)$ & $<0.001$ & 1.90 & $(1.65-2.19)$ & $<0.001$ \\
\hline Major depression & 1.54 & $(1.43-1.65)$ & $<0.001$ & - & - & - \\
\hline Paranoid states & 0.97 & $(0.78-1.20)$ & 0.779 & 1.01 & $(0.81-1.27)$ & 0.928 \\
\hline Neurotic disorders & 2.68 & $(2.36-3.05)$ & $<0.001$ & 1.62 & $(1.42-1.85)$ & $<0.001$ \\
\hline Obsessive-compulsive disorders & 1.04 & $(0.86-1.27)$ & 0.682 & - & - & - \\
\hline Minor depression & 1.61 & $(1.50-1.73)$ & $<0.001$ & - & - & - \\
\hline Mild mental retardation & 0.29 & $(0.18-0.47)$ & $<0.001$ & 1.15 & $(0.69-1.93)$ & 0.597 \\
\hline Other specified mental retardation & 0.08 & $(0.03-0.22)$ & $<0.001$ & 0.25 & $(0.09-0.70)$ & 0.008 \\
\hline Unspecified mental retardation & 0.24 & $(0.15-0.40$ & $<0.001$ & 0.84 & $(0.49-1.43)$ & 0.519 \\
\hline \multicolumn{7}{|l|}{ Anti-psychotics } \\
\hline None & 1.00 & (reference) & & 1.00 & (reference) & \\
\hline First generation & 2.06 & $(1.87-2.27)$ & $<0.001$ & 1.28 & $(1.15-1.41)$ & $<0.001$ \\
\hline Second generation & 0.65 & $(0.44-0.94)$ & $<0.001$ & 0.64 & $(0.44-0.95)$ & 0.005 \\
\hline Both & 1.61 & $(1.42-1.81)$ & $<0.001$ & 1.07 & $(0.92-1.23)$ & 0.118 \\
\hline
\end{tabular}

${ }^{\mathrm{a}} \mathrm{OR}$, odds ratio

badjusted for all variables in table 
depression $(\mathrm{OR}=1.54)$, sleeping disturbance/ insomnia $(\mathrm{OR}=1.19)$, and neurotic disorders $(\mathrm{OR}=1.24)$, including anxiety $(\mathrm{OR}=1.34)$, than those without DES. However, prevalence of DES was significantly lower in patients with dementia $(\mathrm{OR}=0.73)$ and mental retardation $(\mathrm{OR}=0.25)$.

Several previous studies demonstrated greater prevalence of DES in people with depression [3-5, 8, 9]. Furthermore, the severity of DES had a greater impact on the depressive symptoms compared with other psychosomatic symptoms [10]. Several mechanisms may explain the association between depression and DES [11-13]. First, we believe that inflammation may play a key role in the pathogenesis of both depression and DES. In patients with DES, increased production of inflammatory cytokines was found in the tears and conjunctiva, including TNF-a, IFNc, IL-1b, IL-2, IL-6, and IL-8.47-51 [14-16]. Depressive patients were also reported to have higher levels of inflammatory cytokines and neuropeptides in the blood [15-17]. These cytokines and neuropeptides may simultaneously lead to ocular surface inflammation and exacerbation of negative moods. Second, many previous studies reported depressive patients have a lower threshold of pain perception and often complaint worse dry eye symptom compare with patients without depression. "Neuropathic pain" caused by neural dysfunction plays a role in the unreasonable chronic pain in patients with DES and depression [18]. Third, selective serotonin reuptake inhibitors (SSRIs) are a class of antidepressant that have been reported to be significantly associated with DES. It is possible that SSRIs cause an anticholinergic side effect whereby altered serotonin levels affect the sensitivity thresholds of corneal nerves [19]. Further study on the correlation between SSRIs and DES is necessary.

Our study also found that anxiety disorder was correlated with DES, which supports the findings of two previously reported case-control studies [4, 20]. Furthermore, Wen et al. found three significant independent predictors of DES in patients with anxiety, including older age, duration of PD, and the use of an SSRI [4].

There was a significantly increased risk of DES in patients with bipolar disorder $(\mathrm{OR}=1.55)$. Dibajnia et al. showed significant decreased tear break up time in patients with bipolar disorder treated with either lithium carbonate or sodium valproate [5]. However, the mechanism of this pharmacologic effect is not clear.

Older age has been shown to be associated with increased risk of both DES and dementia [1]. Previous studies demonstrated that patients with dementia have a greater risk of developing dry eye and Sjögren's syndrome [21, 22]. However, we found a decreased risk of DES in dementia patients in our multivariate models. This is the first large-scale study to find this association. We believe the risk might have been underestimated because dementia patients may be less likely to report symptoms due to the decline in cognitive function and communication skills.

A major strength of this study was the use of a large cohort study to investigate the association between DES and PD using data from the National Health Insurance Research Database (NHIRD). This database covers approximately $99 \%$ of the country's residents. However, there were several limitations in this study. First, it was a retrospective study and detailed information are not available in the NHIRD, such as socioeconomic status, severity of disease, and laboratory results. Second, we used strict exclusion criteria and definitions for the diagnosis of DES. Only patients with both ICD-9-CM diagnosis code 375.15 and an anatomical therapeutic chemical code for ophthalmological lubricants (ATC code: S01XA) were included in the analysis. This selection bias might have resulted in an underestimation of the prevalence of DES in psychiatric patients, because patients with only mild dry eye symptoms may not need to use any medication. In addition, some patients may seek other medications that are not available on the NHI system.

\section{Conclusion}

This nationwide population-based cohort study demonstrated that among PD patients, DES is highly prevalence in certain subtypes of PD, such as depression, bipolar disorder, and neurotic disorders, after adjusting for the comorbidities.

\section{Abbreviations}

ATC: Anatomical therapeutic chemical code; Cl: Confidence Interval; DEWS: Dry Eye Work Shop; DES: Dry Eye Syndrome; ICD-9-CM: International Classification of Diseases, 9th Revision, Clinical Modification; IL: Interleukins; LHID: Longitudinal Health Insurance Database; NHI: National Health Insurance; NHIRD: National Health Insurance Research Database; OR: Odds Ratio; PD: Psychiatric Disorders; RA: Rheumatoid Arthritis; SLE: Systemic Lupus Erythematosus; SS: Sjogren's Syndrome; SSRIs: Selective Serotonin Reuptake Inhibitors; TNF: Tumor Necrosis Factor

\section{Acknowledgements}

We acknowledge Division of Basic Medical Science, Department of Medical Research, Taichung Veterans General Hospital for assistance with statistical analysis.

\section{Authors' contributions}

$\mathrm{CL}$ and WC analyzed and interpreted the data obtained from Taiwan's NHIRD and were the major contributors in writing the manuscript. They contributed equally to this work. CW and $\mathrm{KL}$ organized the research team, made a substantial contribution to the ethic approval and the work draft. LW and YC made a substantial contribution to the acquisition and revision of the data and table format. YS as the corresponding author design of the work, made substantial contributions to the conception and ensured that that all listed authors have approved the manuscript before submission, including the names and order of authors. All authors read and approved the final manuscript.

\section{Funding}

Not applicable.

\section{Availability of data and materials}

The datasets used and/or analysed during the current study are available from the corresponding author on reasonable request. 


\section{Ethics approval and consent to participate}

The study was approved by the Institutional Review Board of Taichung Veterans General Hospital, Taichung, Taiwan. In this study, the requirement for informed consent was waived because the patients' original identification numbers were anonymized by encryption.

\section{Consent for publication}

Not applicable.

\section{Competing interests}

The authors declare that they have no competing interests.

\section{Author details}

'Department of Ophthalmology, Taichung Veterans General Hospital, 1650 Taiwan Boulevard Sect. 4, Xitun Dist, Taichung 40705, Taiwan, Republic of China. ${ }^{2}$ Graduate institute of biomedical sciences, China Medical University, Taichung, Taiwan, Republic of China. ${ }^{3}$ Department of Ophthalmology,

Taichung Tzu Chi Hospital, Taichung, Taiwan, Republic of China.

Received: 12 February 2019 Accepted: 20 March 2020

Published online: 30 March 2020

\section{References}

1. Gayton JL. Etiology, prevalence, and treatment of dry eye disease. Clin Ophthalmol. 2009;3:405-12.

2. Thulasi P, Djalilian AR. Update in current diagnostics and therapeutics of dry eye disease. Ophthalmology. 2017;124(11S):S27-33.

3. Fernandez CA, Galor A, Arheart KL, Musselman DL, Venincasa VD, Florez HJ, Lee DJ. Dry eye syndrome, posttraumatic stress disorder, and depression in an older male veteran population. Invest Ophthalmol Vis Sci. 2013;54(5): 3666-72.

4. Wen W, Wu Y, Chen Y, Gong L, Li M, Chen X, Yan M, Xiao Z, Sun X. Dry eye disease in patients with depressive and anxiety in Shanghai. Cornea. 2012; 31(6):686-92.

5. Dibajnia P, Mohammadinia M, Moghadasin M, Amiri MA. Tear film break-up time in bipolar disorder. Iran J Psychiatry. 2012;7(4):191-3.

6. Labbé A, et al. Dry eye disease, dry eye symptoms and depression: the Beijing eye study. Br J Ophthalmol. 2013;97(11):1399-403.

7. Szakáts I, et al. The role of health anxiety and depressive symptoms in dry eye disease. Curr Eye Res. 2016;41(8):1044-9.

8. Galor A, Feuer W, Lee DJ, et al. Prevalence and risk factors of dry eye syndrome in a United States veterans affairs population. Am J Ophthalmol. 2011;152:377-84.

9. Wang TJ, Wang IJ, Hu CC, Lin HC. Comorbidities of dry eye disease: a nationwide population-based study. Acta Ophthalmol. 2012;90(7):663-8.

10. Asiedu K, Dzasimatu SK, Kyei S. Impact of dry eye on psychosomatic symptoms and quality of life in a healthy youthful clinical sample. Eye Contact Lens. 2018;44(Suppl 2):S404-9.

11. Liu KC, Huynh K, Grubbs J Jr, et al. Autoimmunity in the pathogenesis and treatment of keratoconjunctivitis sicca. Curr Allergy Asthma Rep. $2014 ; 14: 403$

12. Stevenson W, Chauhan SK, Dana R. Dry eye disease: an immunemediated ocular surface disorder. Arch Ophthalmol. 2012;130:90-100.

13. Barabino S, Chen $Y$, Chauhan S, et al. Ocular surface immunity: homeostatic mechanisms and their disruption in dry eye disease. Prog Retin Eye Res. 2012;31:271-85.

14. Miller $\mathrm{AH}$, Maletic $\mathrm{V}$, Raison $\mathrm{CL}$. Inflammation and its discontents: the role of cytokines in the pathophysiology of major depression. Biol Psychiatry. 2009; 65(9):732-41.

15. Felger JC, Lotrich FE. Inflammatory cytokines in depression: neurobiological mechanisms and therapeutic implications. Neuroscience. 2013:246:199-229.

16. Vriezekolk JE, Geenen R, Hartkamp A, Godaert GL, Bootsma H, Kruize AA, Bijlsma JW, Derksen RH. Psychological and somatic predictors of perceived and measured ocular dryness of patients with primary Sjögren's syndrome. J Rheumatol. 2005;32(12):2351-5.

17. Werner FM, et al. Classical neurotransmitters and neuropeptides involved in major depression: a review. Int J Neurosci. 2010;120(7):455-70.

18. Galor A. Painful Dry Eye Symptoms: A Nerve Problem or a Tear Problem? Ophthalmology. 2019;126(5):648-51.

19. Lovett-Barr MR, Mitchell GS, Satriotomo I, Johnson SM. Serotonin-induced in vitro long-term facilitation exhibits differential pattern sensitivity in cervical and thoracic inspiratory motor output. Neuroscience. 2006;142(3): 885-92.

20. Li M, Gong L, Sun X, Chapin WJ. Anxiety and depression in patients with dry eye syndrome. Curr Eye Res. 2011:36(1):1-7.

21. Yoshikawa K, Hatate J, Toratani N, Sugiura S, Shimizu Y, Takahash T, Ito T, Fukunaga R. Prevalence of Sjögren's syndrome with dementia in a memory clinic. J Neurol Sci. 2012;322(1-2):217-21.

22. Liliang PC, Liang CL, Lu K, Yang SN, Hsieh MT, Tai YC, Wang KW. Populationbased study suggests an increased risk of Alzheimer's disease in Sjögren's syndrome. Clin Rheumatol. 2018;37(4):935-41.

\section{Publisher's Note}

Springer Nature remains neutral with regard to jurisdictional claims in published maps and institutional affiliations.
Ready to submit your research? Choose BMC and benefit from:

- fast, convenient online submission

- thorough peer review by experienced researchers in your field

- rapid publication on acceptance

- support for research data, including large and complex data types

- gold Open Access which fosters wider collaboration and increased citations

- maximum visibility for your research: over $100 \mathrm{M}$ website views per year

At $\mathrm{BMC}$, research is always in progress.

Learn more biomedcentral.com/submissions 